\title{
Modelling scenarios of environmental recovery after implementation of controls on emissions of persistent organic pollutants
}

Comber, Sean

http://hdl.handle.net/10026.1/16266

10.1039/d0em00137f

Environmental Science: Processes \& Impacts

Royal Society of Chemistry (RSC)

All content in PEARL is protected by copyright law. Author manuscripts are made available in accordance with publisher policies. Please cite only the published version using the details provided on the item record or document. In the absence of an open licence (e.g. Creative Commons), permissions for further reuse of content should be sought from the publisher or author. 
1 This is an accepted revised copy - for full article please visit the

2 ESPI website or click: https://doi.org/10.1039/D0EM00137F for a published

3 copy

4

Modelling scenarios of environmental recovery after implementation of controls on emissions of persistent organic pollutants

7

\section{S. D. W. Comber ${ }^{1}$, M. J. Gardner ${ }^{2}$, C. Constantino ${ }^{2}$, S. Firth ${ }^{2}$, A. Hargreaves ${ }^{2}$ and R Davies $^{2}$}

${ }^{1}$ Plymouth University, B531, Portland Square, Drake Circus, Plymouth, Devon, PL4 8AA UK

${ }^{2}$ Oasis Business Park Eynsham Oxford OX29 4AH United Kingdom. Tel: +44 1865882828 ; email: sean.comber@plymouth.ac.uk

\section{Abstract}

Comparison of monitoring data with toxicologically-derived environmental quality standards (EQSs) forms the basis of assessments of the quality status of the water environment. Having established the status quo, the logical next step is to address instances of non-compliance with EQSs by applying remedial measures, including reducing the use or at least the emission of the substances of concern or by taking steps to reduce concentrations already present using technological solutions such as enhanced wastewater treatment. The selection of suitable remedial measures must be a compromise between cost, likely effectiveness and the timescale over which improvements might be acceptable. The decision on overall environmental management has also to take into account the need for demonstrable progress; this might mean that it is preferable to address some more readily achievable goal rather than to attempt to solve a more serious, but ultimately intractable problem. This paper describes the development and application of a generic modelling tool that provides a way of assessing the potential requirements for remedial actions and their likely outcomes over a timescale of up to forty years taking account of sediment partitioning, environmental degradation and biological accumulation. The tool was validated using a detailed UK wastewater treatment works effluent discharge dataset. Examples involving several chemicals that are of current concern are provided. Some substances (e.g. tributyltin, PFOS) are identified as likely to meet EQS values in sediments or biota in a relatively short timescale; others (PAHs, DEHP) appear to represent more intractable problems.

Key words: priority chemicals; effluents; seasonality; water quality; rivers 


\section{Introduction}

The accumulation in the environment of substances that are persistent, bioaccumulative and toxic (PBT) can represent a risk to wildlife and the human population as a result of bioaccumulation and biomagnification through food chains. This issue has been identified as an important global issue since organo-chlorine based pesticides and industrial chemicals were found to be bioaccumulating within the food chain with demonstrable negative impacts in many cases(1). In recognition of this, the Stockholm Convention on Persistent Organic Pollutants (POPs) was adopted in May 2001 and entered into force in May 2004. Initially this protocol identified a ban on 9 organochlorine-based POPs; it restricted the use of DDT to malaria control, and curtailed inadvertent production of dioxins and furans. Subsequently, further chemicals have been added to the list for control or elimination where they meet PBT criteria; these include brominated diphenylethers, perfluorooctanesulphonic acid (PFOS) and perfluorooctanoic acid (PFOA) additional chlorinated benzenes and phenols and chlorinated paraffins. Other substances such as tributyl tin (TBT) which owing to harmful effects on dog whelks was banned in antifoulant paint formulations on vessels by the International Maritime Organisation in 2008(2). For other chemicals there may be local or regional controls on its use such as the pyrethroid insecticide cypermethrin(3) and hexabromocyclododecane (HBCDD) which is listed under the Stockholm Convention and is present in Annex 1 of Regulation (EC) No 850/2004. This prohibits its production, use, import and export. Chemicals such as methyl mercury have been known to be an environmental hazard for decades but are released into the environment from natural as well as anthropogenic sources. This has been addressed by controls being placed on concentrations in food(4).

Although world-wide policies such as the Stockholm Convention adopts a hazard-based approach and identifies substances for production controls or target environmental controls for unintended releases, other (often regional) legislation (e.g. EU Water Framework Directive and $\mathrm{REACH}$ ) takes a risk-based stance with the derivation of Environmental Quality Standards (EQS) to protect the most vulnerable biota (e.g.(5-12)). However, measures to achieve reduction in the inputs of such substances do not always produce immediate effects in terms of the observed environmental concentrations (and hence of perceived risk). This can be related to the residual reservoir of contaminant in the environment, uses not included in the applied measures as well as unauthorised uses and to the challenges of determining concentrations, often at extremely low levels, in the targeted organisms or matrix of interest. Where remedial action is taken to reduce pollutant concentrations, it can therefore be difficult to determine the effectiveness of control measures. 
Wastewater treatment works (WwTW) represent a potential major contributor of chemicals to the environment because they receive discharges from domestic, commercial and industrial sources as well as legacy issues such as landfill leachate and runoff from contaminated land (13). Whilst a proportion of any given trace chemical might volatilise or degrade during the treatment processes, or sorb to the treatment process sludge(14), concentrations in sewage effluents can be a cause for concern(15,16). Modelling of the rates of change of contaminant concentrations in effluents constitutes an important regulatory tool (supplemented by monitoring) in prioritising control measures and assessing their current and likely future effectiveness.

The development of generic or evaluative models is not a new approach to environmental impact assessment. The fate and transport of chemicals in a hypothetical, yet standard (Unit World) environment has been widely used to assess general features regarding the chemical fate or to screen and prioritize chemicals based on a uniform assessment metric. These fugacity based models, utilise concentration and mass balance, equilibrium (between media), rate controlled mass transfer, first-order decay, and advective exchange with the external environment to predict fate and behaviour(17-19). These models are can either be used for bespoke, site-specific applications or provide a general guide to environmental improvement. Depending on specific purposes, the models have been run at both steady and non-steady state (dynamic)(19,20), for general use establishing the reversibility of environmental contamination with POPs in a regional setting(21), the response of environmental contamination in the Arctic to the reduction in the global emissions(22), or scenarios of emissions associated with industrial production, use and waste disposal(23).

Such models have been applied to POPs such as brominated diphenylethers, PCBs, hexachlorobenzene, atrazine, short chain chlorinated paraffins and hexachlorocyclohexane for example(24). Furthermore, such models have been developed the multi-media model concept yet further to encompass chemical classification, temporal persistence, spatial range, human exposure, risk, and uncertainty(25-30). Most recently this broad approach has led to the development of the ChemFate model which combines four different fate and transport models and was applied to chemicals in current use with radically different physico-chemical characteristics, such as copper sulphate, nano copper oxide, chlorothalonil and cyprodinill(31).

With improved access to databases and ever more sophisticated computing software there is a range of other available models and decision support tools available for environmental modelling of chemicals. These include (1) domain knowledge modelling which has been 
applied to wastewater management via the environmental decision support tools (EDSS) and ontology-based wastewater environ-mental decision-support systems (OntoWEDSS)(32); water quality modelling applied to eutrophication in Hong Kong(33) and river water assessment(34); (2) data mining using remote sensing data for surface waters(35) and in groundwater assessment(36); (3) Bayesian Networks for urban pollution prediction(37) and emergent water pollution accidents risk analysis(38); or (4) a combination of these approaches for water quality assessment(39). Water quality models are common and are available as open source or commercially supported packages but are largely stochastic such as SIMCAT which provides probability based estimates at any given instance in time (typically 1 to 3 year periods $^{(13)}$ or time series models such as INCA which can predict processes and trends but require significant flow and land use data(40). Trends in POPs concentrations have been monitored and modelled in biota from Polar regions(41). However, there is no 'off the shelf' modelling tool available to fulfil the needs of being able to simply predict the length of time required to achieve any given environmentally safe concentration for PBT chemicals at a local level for meeting legislation such as the WFD.

Models are often developed as bespoke tools for meeting a defined purpose, whether for industrial, regulatory or academic purposes. Consequently there is rarely an off-the-shelf model available that fulfils all of the requirements of any given situation. The discharge of wastewater into receiving waters is the main 'industrial' input of contaminants into the aquatic environment of many countries including the UK. To be able to predict the impact of regulation of POPs on long term concentrations in the aquatic environment as a result of WwTW discharges and to be able to assess compliance with EQS is of vital importance to regulatory agencies and sewage treatment operatives alike. This paper describes a novel prototype tool that has been developed to specifically allow a user to predict the likely future effect of measures to control environmental inputs from WwTW, based on current data that provide an estimate of continual year-on-year percentage reduction.

This approach addresses the situation primarily where EQS style standards have been set for biota or for surface waters where sediment concentrations might be an additional important factor. A key feature is to determine the likely time taken to comply with an EQS and thereby to prioritise action on substances for which measures are likely to be fruitful within a desired timescale. The tool makes it possible to estimate (and visualise) the effect of a proposed change in contaminant input on the likely environmental outcome over a 20-40-year planning horizon. The tool is capable of being applied to all chemicals, even those of emerging concern with lower Kow values, where it might be shown that bioconcentration via sediment and/or biota is not a threat to compliance with EQS. However owing to the established PBT properties 
147 of many established chemicals concern, the modelling tool was primarily developed to address 148 persistent contaminants that: a) are of concern in biota and b) are taken up by biota primarily 149 though exposure (though feeding or otherwise) to contaminated sediments. The initial 150 approach explained here outlines the development and examples of outputs, subsequent 151 developments have involved extensive improvements to the user interface and the output 152 visualisations, not discussed here. The tool is intended to be used in regulatory screening 153 scenario testing for generic risk assessment, not a site specific application. By taking this 154 approach it is possible to prioritise possible remedial action for regulated substances in biota 155 in relation to the likelihood that prompt action might feasibly be rewarded by worthwhile 156 progress towards compliance and to manage expectations for refractory substances that 157 would be likely to pose difficulties in meeting current standards. 


\subsection{Choice of test chemicals}

The development of his tool, therefore, focused on an exposure pathway relating to substances that are of interest because of their environmental persistence and their tendency to adsorb to sediments. To demonstrate the efficacy of the approach an array of chemicals from different sources and with differing physico-chemical characteristics was selected from a longer list of priority chemicals (ESI, Table S1). Brominated diphenyl ethers, diethylhexylphthalate (DEHP), tributyltin (TBT), hexabromocyclododecane, and the fluorocarbons (PFOS and PFOA) have been subject to significant controls or bans to prevent or minimise release to the environment. Their PBT properties, however, means that environmental regulators need to be able to predict the time period that will be required to meet compliance with set objectives. Two polynuclear aromatic hydrocarbons (benzo(a)pyrene and fluoranthene) were selected as they are also PBT chemicals but are capable of being generated naturally and the significant legacy contamination of the environment means any die-away may be much slower than anthropogenic PBT chemicals. Cypermethrin offered a contrast, as it is less persistent, is still being used under more restricted circumstances than previously, but is of concern from a toxicity point of view.

Substances, having different chemical properties, for which the above modelling approach might not be applicable, or for which the conceptual model might need to be modified, include metals which do not decompose, and substances such as many pharmaceuticals that have a lower affinity for particulate matter. In these cases, different approaches would be appropriate to the estimation of exposure routes to biota and their ultimate environmental fate.

\section{$2.2 \quad$ The approach}

The development of the estimator tool itself is intended to provide an assessment of the effects of pollution control interventions for different trace substances with an output visualising change and indicating the likely time taken (for any chosen magnitude of reduced input) to result in compliance with the EQS or other critical concentration values. Mechanistically, the tool concentrates on the net overall outcome of the concurrent processes of contaminant addition to the environment and of removal by processes of natural purification (degradation and sorption to particulates). The tool is not an attempt to model specific conditions at any particular location. To do this would require information on the nature, size and configuration 
of the receiving environment and specific detail of local inputs and environmental processes that are neither readily available nor in many cases even understood.

In order to make the outputs meaningful and to facilitate comparisons between substances and different control measures a notional receiving environment is set up as part of the tool. This comprises a nominal discharge for a WwTW corresponding to 50,000 population equivalent, discharging to a watercourse that provides a nominal threefold dilution. Such a dilution represents a reasonable worst case that takes account of the dilution for discharges that for more than $98 \%$ of sewage treatment load in the UK for example(13). These assumptions effectively determine the respective sewage effluent and river flow regimes. This specified dilution/flow regime is then used in conjunction with the likely settling time of discharged particulate matter to establish the width and length of the impacted watercourse and hence the receiving sediment mass. In all outputs discussed here, this notional "sediment target" is held constant, although the possibility to make alterations to the preceding assumptions remains an option.

The operation of the estimator tool is to input different nominal control measures (the reduction in concentration achieved is entered - the mechanisms of control are not considered) and to determine the effect of these measures on resultant sediment and biota concentrations. Key assumptions are that:

a) Contaminants can be discharged from a) the conceptual WwTW discussed above, or b) from other point or diffuse sources in the area under consideration. A measured concentration in sewage effluent is the basis of the former inputs. Estimation of the latter contribution from non-WwTW sources is considered as a multiple of the WwTW load. This is based on data provided by recent UKWIR catchment monitoring programmes ${ }^{(42)}$. These studies compared the in-river concentrations with known sewage effluent sources. Any contributions to the former that were not assignable to the latter were considered to be "non-WwTW" sources;

b) The pathway of a contaminant is via adsorption to sediment, settlement and then by transfer (by exposure or through the food chain to aquatic or benthic organisms (biota)). The implication of this is that dissolved contaminants are not taken into account. This assumption is proposed as a workable proposition for PBT substances because of their affinity for sediments; its adoption for more hydrophilic substances where exposure of biota in the water column might not be appropriate. 
Knowledge of the concentration of contaminants in the effluent discharge and their characteristics regarding partitioning to particulate matter then makes it possible to calculate the load discharged and the extent to which this will contaminate the sediment target referred to above. This resulting sediment concentration is then used to estimate a concentration in biota using the convention of a biota-sediment concentration factor (BSCF)(43).

\section{$2.3 \quad$ Calculations}

Further information on the calculations and in particular the units used are provided in the Electronic supporting information (ESI Tables S2 and S3). Contaminants in the environment are in a constant state of flux. Processes of addition and removal combine to determine whether or not concentrations will tend to increase, decrease or, if these processes are in balance, stay the same. Determination of the fate and behaviour of chemicals in the environment is essentially a question of understanding rates of change. The rate of change in concentration of an environmental contaminant is determined by two factors. Firstly, there is the rate of disappearance of the substance; this can be assumed to be related to how much substance is present at any given time. This has been considered to follow a so-called first order exponential decay curve. The second factor is the rate at which the substance is added by the processes that raised the concentration in the first place, in this case, discharges from wastewater treatment works (WwTW) and release from other unspecified sources (categorised as non-WwTW inputs).

The rate of change of concentration may therefore be given by equation (1):

252

$\frac{d y}{d x}=-k \times y+S \times x$

253

Where $y$ is concentration, $x$ is time (e.g. years); $S$ is the amount of substance added to sediment per unit time and $k$ is the decay rate constant $=[\ln (2) /($ the half-life $)]$. Hence:

This is a first order differential equation of a standard form that can be solved for $y$ to give the solution below:

261

262

$y_{x}=c_{1} \times e^{-k x}+c_{2}$ 
where $c_{1}$ and $c_{2}$ are constants of integration. The constant $c_{2}$ is calculated as $-s / k ; c_{1}$ relates to conditions at time $x\left(S_{x} /-k\right)$, hence:

$y_{x}=\frac{s_{x}}{-k} \times e^{-k x}+\frac{s_{0}}{k}$

268

269

$\mathrm{S}_{0}$, the rate of contaminant addition to sediment is considered in the first instance to be related to a wastewater effluent discharge and hence is dependent on the concentration in the effluent, the flow of effluent in unit time and the mass of the receiving sediment target. The last two of these quantities can be taken (for any given situation) to be constants since sewage flow is largely dependent on the population equivalent of the WwTW and the sediment target (the quantity of sediment in the receiving river reach that is available to be contaminated) is fixed. Hence $S(\mu \mathrm{g} / \mathrm{kg} / \mathrm{yr})$ is assumed to be the concentration of contaminant in the particulate phase in the effluent $(\mu \mathrm{g} / \mathrm{l})$ multiplied by a constant expressed ( Const $_{\text {flow/sed }}$, see below) as $\mathrm{l} / \mathrm{yr} / \mathrm{kg}$.

The above equation (1) will generate a series of curves showing the change in concentration based on what the stating conditions are. This concept is demonstrated in Figure 1 which illustrates that whatever the starting condition the concentration will tend to the same equilibrium value which is equal to $S_{0} / k$. How long it takes to reach equilibrium depends on the value of $\mathrm{k}$.

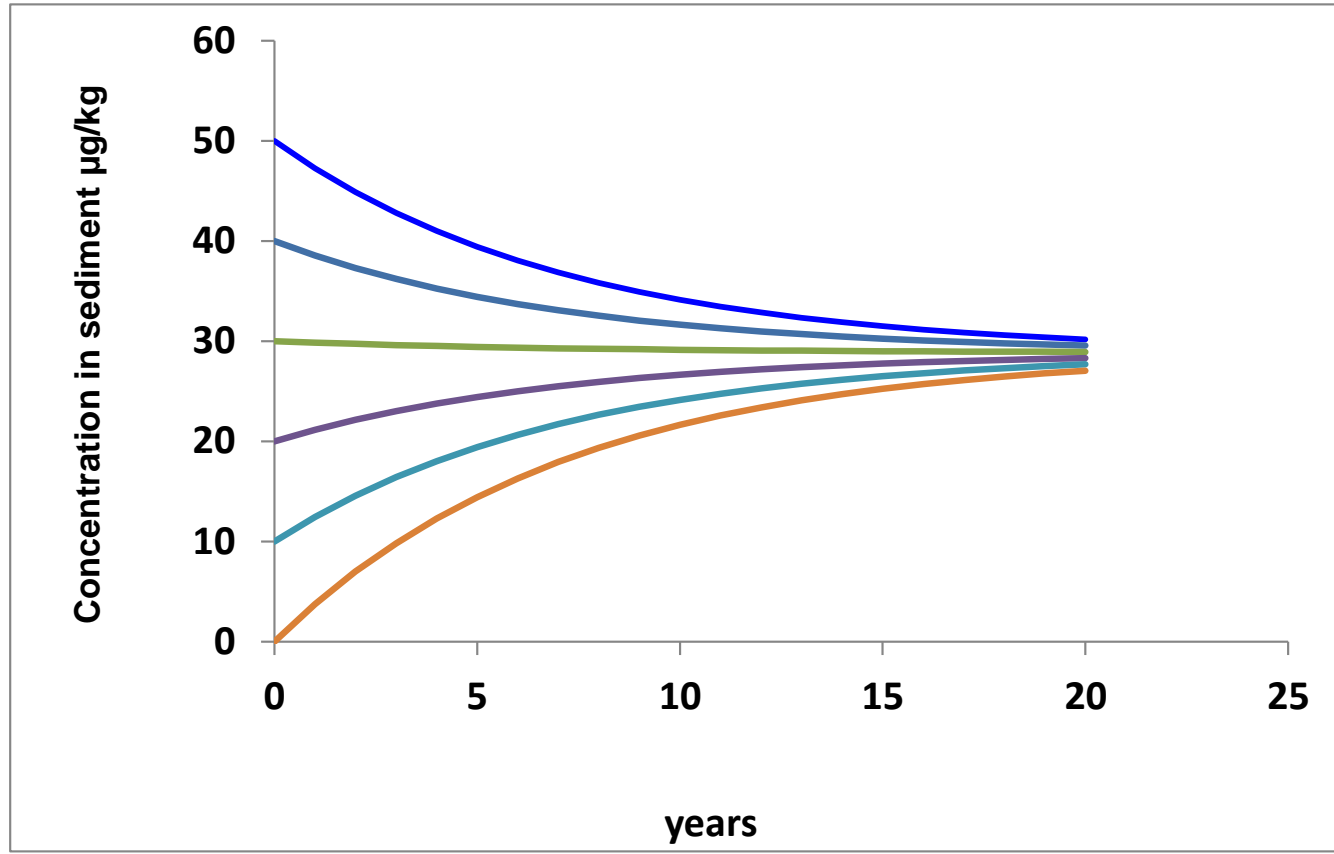

Figure 1 Representation of decay curves generated for different chemical starting concentrations, but tending towards the same equilibrium value which is equal to SO/k 
The assumptions made here are that the notional WwTW pe is 50,000 , the volume discharged per person is $290 \mathrm{l} / \mathrm{d}$ (giving a total of $7.25 \mathrm{Ml} / \mathrm{d}$ ) and that the sediment target corresponds to a river reach that provides a dilution of approximately 3 fold (the length and width of the river are used to determine a stretch of river that would allow sediment to settle based on Stokes Law. In this case the river is $2.5 \mathrm{~m}$ wide and the mixing length is $620 \mathrm{~m}(44)$. The resulting sediment target for an accessible depth of sediment of $5 \mathrm{~cm}$ is $200,000 \mathrm{~kg}$ based on a density of $1.6 \mathrm{~g} / \mathrm{cm}^{3}$. The dissolved component of the effluent discharge is assumed to travel downstream and is not considered further.

Hence, the initial rate of contaminant input is calculated as:

$$
S_{0}=C_{\text {particulate effl }} \times \text { Const }_{\text {flow } / \text { sed }}
$$

Where Const $_{\text {flow/sed }}$ is explained above and $C_{\text {particulate effl }}$ is the concentration of contaminant in the particulate phase

$$
C_{\text {particulate effl }}=1-\left[\frac{C_{\text {total }}}{1+\left(K_{p} \times S P M\right)}\right]
$$

$C_{\text {total }}$ is the total contaminant concentration $(\mu \mathrm{g} / \mathrm{l}), \mathrm{K}_{\mathrm{p}}$ is the partition coefficient of the contaminant for sewage solids $(\mathrm{l} / \mathrm{kg})$ and SPM is the concentration of suspended particulate matter in the effluent/river $(\mathrm{kg} / \mathrm{l})$ - assumed to be $0.000005(5 \mathrm{mg} / \mathrm{l})$.

$\mathrm{K}_{\mathrm{p}}$ can be a measured value if a credible one is available, or it can be derived from the octanol/water partition coefficient Kow as:

$$
\log K_{p}=f o c \times\left(0.72 \times \log K_{o w}+0.42\right)
$$

foc, the fraction of organic carbon in the sediment and for sewage solids is assumed to be 1.0 , but can be adjusted to a more realistic value such as 0.33 where necessary ${ }^{(45)}$. Matters become more complicated when a reduction (as a result of pollution control measures) in the input concentration is considered. This has been expressed as an annual percentage rate of reduction (APR) which is converted to a rate of reduction constant, $\mathrm{k}_{\text {red }}$, that is applied to the values of $S$ for each succeeding year of the simulated decay in overall concentration. This leads to the input at year $[\mathrm{x}]$ being estimated as:

$$
S_{x}=S_{0} \times\left(1-k_{r e d}\right)^{x}
$$

In summary, the sediment concentration in year $[x]$ is given by the sum of 
- What remains of the initial concentration in year [x]; and,

- The combined effect of what has been added up to year $[x]$ and of this what has decomposed.

In mathematical terms this is:

$y_{X}=\frac{S_{0}}{k} \times e^{-k x}+\frac{s_{x}}{-k} \times e^{-k x}+\frac{S_{x}}{k}$

The above representation is one of a system undergoing equilibration between the constant addition of a contaminant and its tendency to decay (decompose) with time. The situation becomes more complicated when the rate of addition itself changes during the modelling period under consideration. At this point it is necessary to consider some practical examples that require certain enabling or simplifying assumptions. Clearly, it is important to keep these assumptions in mind.

\subsection{Testing}

The text below lists the main considerations relating to the construction of a realistic depiction of the behaviour of a contaminant to the competing effects of decomposition and addition.

Firstly, there is the question of where the simulation starts, i.e. what is the state of contamination at year zero? It is accepted that that historical emissions for many of the test substances were considerably higher in the past when they were used without control or mitigation. However, gaining accurate data for historic concentrations is challenging owing to advances in analytical capabilities and the fact that observed concentrations were highly variable and often localised. An extreme case would be to assume starting with a pristine, uncontaminated sediment, except that is unrealistic and as can be seen from Figure 1 (orange curve) there would be a period over which the equilibrium concentration is established within the sediment. Beginning with a concentration at the equilibrium value is the simplest approach (and the one most often chosen) because it represents contamination over the longer term, thereby is a way of accounting for historic emissions and avoids the complication of this initial phase of equilibration. Other options have been explored but are not dealt with here.

There are several approaches to using the illustrative tool:

\section{Starting conditions are likely to:}


a) use the known inputs as the determinant of equilibriums starting conditions. This might be valuable when inputs are known and there is then the ability to check whether or not the predicted equilibrium value is of the same order as any observed values;

b) be based on the observed values and to examine the likely direction of travel when current inputs are entered into the tool. This might indicate either a discrepancy between the two sets of observations or errors in other inputs. In particular, if the sewage effluent inputs lead to underestimation of environmental levels, it might be the case that there are additional inputs from other sources.

The approach used here for illustrative purposes was to use an estimate of the equilibrium concentration (calculated from the estimated inputs) and to proceed to assess the likely effects of any possible remedial measures.

\section{The nature of projected changes.}

Linear reductions at constant rate should be ruled out as they would imply the attainment of zero or negative concentrations. The two most worthwhile approaches are to assume a constant percentage rate of decline (effectively an exponential decay curve) with (possibly) the option at some point in the future of a further step change in input rate, which could come about from the cessation of a discharge, via for example, further effluent treatment. The use of a single decay curve can be unproductive as these tend to flatten out leading to a potential "no progress" situation, the option of further measures leading to a future boost to decline might be of value (provided of course that there is reason to believe that such measures might be applied). Such a second phase of remediation was also included.

\section{$2.5 \quad$ Scenario testing}

Scenario modelling is essentially an approach whereby a model is used to examine the likely effect of a series of actions or, more simply, to answer "what if" type questions.

Consequently, the estimator tool was used to evaluate the likely outcome of five different level of reduction in inputs:

1) Scenario 1: an annual percentage rate of reduction (APR) of 10\% in the WwTW input;

2) Scenario 2: an APR of $10 \%$ in the WwTW input, accompanied an APR of $10 \%$ in non-WwTW sources;

3) Scenario 3: an APR of $7 \%$ in the WwTW input, accompanied an APR of $5 \%$ in nonWwTW sources. The rationale behind that is that these reductions were agreed to be 
both realistically achievable and not so small as not to be measurable. Two more ambitious scenarios were also explored:

4) Scenario 4: an APR of $14 \%$ in the WwTW input, accompanied an APR of $5 \%$ in nonWwTW sources. is likely to be more realistic than that scenarios 1 and 2 insofar as these reductions are more likely to be achieved; and,

5) Scenario 5: an APR of $21 \%$ in the WwTW input, accompanied an APR of $5 \%$ in nonWwTW sources.

In scenarios 3-5 the reduction on non-WwTW sources was kept at 5\% because it was judged that these might be more difficult to establish and to address owing to their diffuse nature.

401

Physico-chemical data utilised for input data are summarised in Table 1 based on data obtained from the literature (ESI, Table S4). It is acknowledged that the measurement and reporting of these key physico-chemical properties varies considerably as seen in Table S4, depending on the ambient environmental and/or test conditions, temporal and spatial variability, as well as sampling and sample pretreatment methodologies. Consequently values often range over more than an order of magnitude. However, the benefits of a model are that this variability may be tested via a full sensitivity analysis. 
Inputs used in scenario modelling

\begin{tabular}{|c|c|c|c|c|c|c|c|}
\hline Input & $\begin{array}{c}\text { Input } \\
\text { concentration } \\
- \text { WwTW } \\
\text { source }\end{array}$ & $\begin{array}{l}\text { Input load to } \\
\text { sediment - non- } \\
\text { point source as } \\
\text { multiplier of } \\
\text { WwTW input }\end{array}$ & $\begin{array}{l}\text { Half-life } \\
\text { (t 1/2) of } \\
\text { substance } \\
\text { in } \\
\text { sediment }\end{array}$ & $\begin{array}{c}\text { BSCF to } \\
\text { biota }\end{array}$ & $\begin{array}{l}\text { Log Kp } \\
\text { value }\end{array}$ & Biota EQS & $\begin{array}{c}\text { Sediment } \\
\text { critical } \\
\text { value }\end{array}$ \\
\hline Units & $\mu \mathrm{g} / \mathrm{l}$ & $\mu \mathrm{g} /$ year & years & & $1 / \mathrm{kg}$ & $\mu \mathrm{g} / \mathrm{kg}$ & $\mu \mathrm{g} / \mathrm{kg}$ \\
\hline \multicolumn{8}{|l|}{ Substance } \\
\hline TBT & 0.00023 & 0.4 & 1.6 & 10 & 4.7 & $\mathrm{n} / \mathrm{a}$ & $1.1(\mathrm{a})$ \\
\hline Methyl-Mercury & 0.0029 & 1.6 & 0.0041 & 100 & 6.46 & 20 & \\
\hline HBCDD & 0.011 & 0.8 & 0.27 & 1 & 6 & 167 & \\
\hline Cypermethrin & 0.00034 & 1.3 & 0.027 & 0.2 & 5.5 & $\mathrm{n} / \mathrm{a}$ & $0.2(b)$ \\
\hline PFOS & 0.0075 & 1.0 & 3 & 1.5 & 3.15 & 9.1 & \\
\hline PFOA & 0.0085 & 10.1 & 3 & 1.6 & 2.70 & $9.1 \mathrm{c})$ & \\
\hline Benzo(a)pyrene & 0.0049 & 6.1 & 1.94 & 1.3 & 4.81 & 5 & \\
\hline Fluoranthene & 0.013 & 0.9 & 1.14 & 0.5 & 4.23 & 30 & \\
\hline DEHP & 0.76 & 0.4 & 0.04 & 1 & 5.9 & $n / a$ & $180(c)$ \\
\hline BDE47 & 0.000018 & 0.4 & 0.45 & 4 & 6 & 0.0085 & \\
\hline
\end{tabular}

Notes: Sediment critical values inserted on the bases shown below where no biota EQS has been set

a) TBT $9 \mu \mathrm{g} \mathrm{Sn} / \mathrm{kg}$ dry weight, corrected for $1 \%$ TOC in sediment(46).

b) Cypermethrin sediment EQS of $0.2 \mu \mathrm{g} / \mathrm{kg}$ dry weight(47).

413

c) For PFOA the EQS value for PFOS has been inserted to facilitate compliance estimation

d) USEPA sediment screening benchmark value $180 \mu \mathrm{g} / \mathrm{kg}$ dry weight for DEHP(48). 


\section{$418 \quad 2.6 \quad$ Validation}

419 Limited validation was possible using recent UK data obtained for WwTW effluent 420 concentrations between 2013 and 2019 inclusive. The UKWIR CIP is a monitoring programme 421 sponsored and designed by the UK Water Industry with the aim of prioritising any possible 422 required action on effluent quality required in order to assist compliance with current regulation 423 on surface water quality (further details are provided in (42)). In this context, data have been 424 obtained from approximately annual tranches of monitoring undertaken at in 2013, 2016, 2017, 4252018 and (more or less completed) 2019. For each tranche of analyses effluent quality data 426 were obtained for between 140 and 180 different WwTW. This constitutes a six-year period of 427 testing from which it is possible to estimate a monitoring-based value for an annualised 428 percentage rate of change accumulated over more than 700 sites of effluent concentration for 429 a range of trace contaminants. Of the substances of interest here data are available for DEHP, 430 TBT, triclosan, benzo(a)pyrene and (as a representative of BDEs) BDE 47.

\subsection{Limitations}

432 The purpose of this model is to take readily available physico-chemical data combined with 433 release scenarios to be able to establish compliance against sediment and/or biota standards. 434 As it stands the development and application of the tool does not allow for site-specific cases 435 nor allows the input of ambient environmental parameters such as salinity, temperature and $436 \mathrm{pH}$ as it was outside of the scope of the research and the aims of the tool's development. 437 However, it should be noted that parameters included in the tool such as partition coefficients 438 and decay rate constants do reflect ambient $\mathrm{pH}, \mathrm{T}$ and salinity. Consequently, the tool may be 439 applied to other scenarios where ambient conditions significantly differ from typical UK 440 environments, for example hotter climates or more acidic waters by amending the decay rate 441 constant (likely to be higher in warmer environments) or partition coefficient (based on 442 chemical pka) respectively. 


\section{$443 \quad 3 . \quad$ Results and discussion}

\section{$444 \quad 3.1 \quad$ Sensitivity analysis}

445 Reliable regression-correlation based sensitivity measures are key to ranking water quality 446 model parameters(49). Environmental modelling exercises usually initially yield a single figure 447 (estimate) of the desired output. In this case the figure is time in years to reach compliance 448 with a quality standard. There is a risk that an output of this kind can be taken to be an absolute 449 prediction. In order to avoid this mistake, it is important to provide some indication of the 450 uncertainty that might reasonably be associated with the output value, of its sensitivity to 451 different inputs and also to rank the input values in order of importance to the overall reliability 452 of the calculations that have been made. As part of the scenario analysis of the estimator tool, 453 the effect on the output of variation of the key input parameters, i.e. the substance partition 454 coefficient $\left(K_{p}\right)$, the half-life in sediment $\left(t_{1 / 2}\right)$ and the BSCF was undertaken. This took the 455 form of a set of 1000 calculations for each substance, in each of which, the values of these 456 three inputs were varied within a plausible range that might reflect uncertainty in the value 457 chosen. The range and variability of the resulting output of this semi partial correlation were 458 then examined.

459 The measures of the variation in inputs can be described in terms of the coefficient of variation 460 (CoV), the standard deviation of value divided by the mean. After due consideration, the 461 following CoV values were selected: $\log K_{p} 0.05$, half-life 0.2 years and BSCF 0.1 . Figure 2 462 shows the ranges of variation for nominal inputs of $\log K_{p}=4.7, t_{1 / 2}=1.6$ years and BSCF $=10$ 463 fold. Clearly, in practice, the nominal values that are relevant to the substance of interest would 464 be entered. 

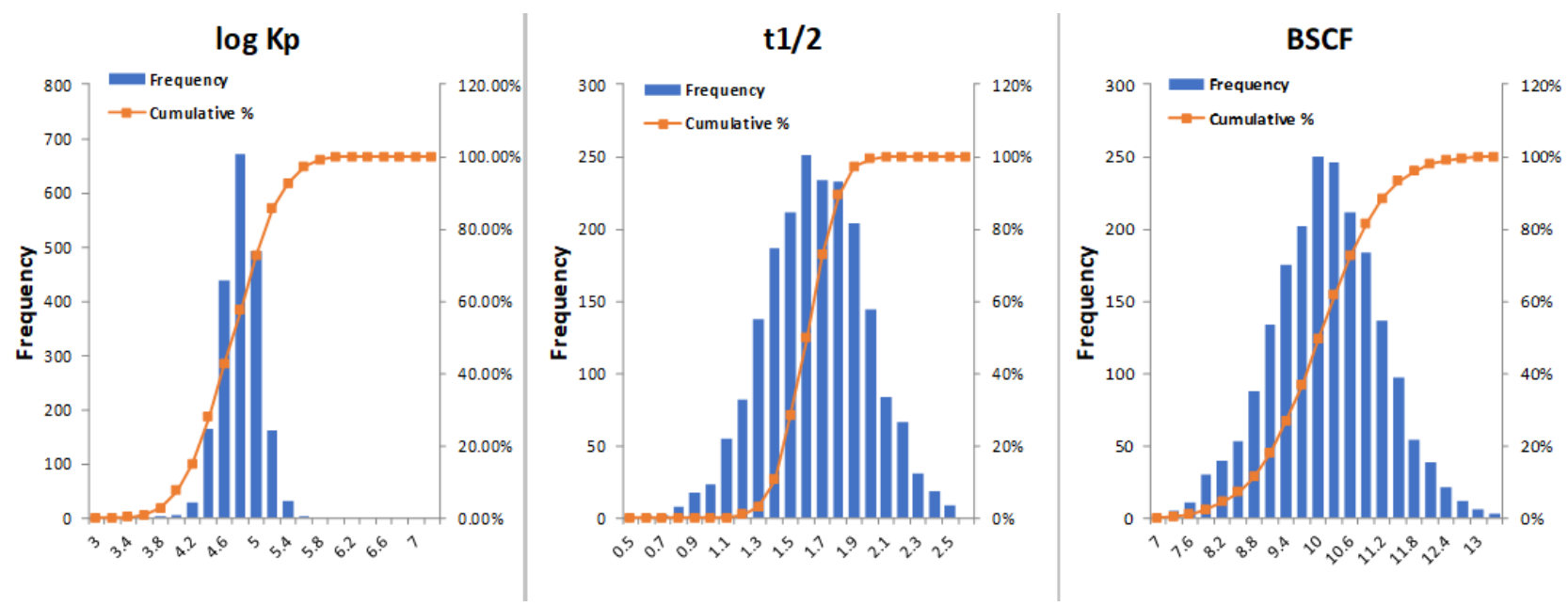

Figure 3

Ranges of input variations for nominal inputs of $\log \mathrm{Kp}=4.7, \mathrm{t}_{1 / 2}=1.6$ years and BSCF $=10$ fold assuming CoV values of log Kp 0.05 , half-life 0.2 years and BSCF 0.1

The effect of this variation in inputs on the output time to compliance was assessed from the 1000 output values and expressed as a $25^{\text {th }}-75^{\text {th }}$ percentile range (which was found to be symmetrical about the mean value).

The relative importance of the three inputs was also evaluated via a multiple linear regression on the outputs. The outcome of this depended on the actual value of the inputs in a complex way:

- BSCF, being merely a multiplier, was found to be of the least importance for the six substances for which there were biota EQS values;

- Where the value of $\log K_{p}$ was in the range $4.5-6$, log $K_{p}$ tended to be the most influential factor. This is because over this range of $\log K_{p}$ values, the value of $\log K_{p}$ has a marked controlling influence over the proportion of substances that is associated with the particulate phase. For a log $\mathrm{K}_{\mathrm{p}}$ of 4.5 at a typical total suspended solids concentration of river water (5 mg/l), approximately $13 \%$ of the substance will be associated with particulates (and therefore be part of the load to sediment), whereas for $\log K_{p}$ of 6 over $90 \%$ of the substance load is in particulate form (at equilibrium). Consequently log $K_{p}$ had significant impact on TBT, Me-Hg, HBCDD, cypermethrin, $\mathrm{BaP}$, fluoranthene, DEHP and BDE47. The persistence and hydrophobic nature of many POPs, in particular PCBs has been extensively studied and the slow rate of disappearance from the environment well characterised $(50,51)$. 
- If the value of $\log \mathrm{K}_{\mathrm{p}}$ is outside this critical range the half-life value can become the most important factor, particularly if it is low, where variation makes a larger difference. Reported environmental half lives for chemicals are notoriously variable (even when using standardised tests such as OECD308) owing to varying ambient conditions which tests have been typically carried out including, temperature, sediment type, chemical concentration, redox conditions, water quality, microbial assemblages and acclimatization etc(52).

Modelling uptake of PCBs and dioxins into biota (including human) key factors were identified as half-lives of the chemicals, body weight variability, lipid fraction, food assimilation efficiency, physiological processes (uptake/elimination rates), environmental exposure concentrations (sediment, water, food) and eating behaviours ${ }^{(53)}$. One thing that is important to stress is that this sensitivity analysis does not reflect the likely outcome or insure against serious error caused by using a completely inappropriate/wrong value for an input to the estimator tool. The implicit assumption is that a reasonably representative estimate of $\log \mathrm{K}_{\mathrm{p}}$, BSCF or half-life is available in the first place.

\subsection{Scenario modelling}

The outputs of the estimator tool for the five scenarios are summarised in Table 2. 


\begin{tabular}{|c|c|c|c|c|c|c|}
\hline & Scenario 1 & Scenario 2 & Scenario 3 & Scenario 4 & Scenario 5 & Bespoke scenario \\
\hline & $\begin{array}{l}\text { Time in years } \\
\text { to meet EQS } \\
\text { value at } 0.1 \\
\text { APR reduction } \\
\text { of WwTW } \\
\text { emissions } \\
\text { without control } \\
\text { of diffuse } \\
\text { sources } \\
10 \% \text { APR } \\
\text { WwTW only }\end{array}$ & $\begin{array}{l}\text { Time in years } \\
\text { for reduction } \\
\text { of both types } \\
\text { of inputs }\end{array}$ & $\begin{array}{l}\text { Time in years } \\
\text { for reduction } \\
\text { of both types } \\
\text { of inputs }\end{array}$ & $\begin{array}{l}\text { APR: } \\
\text { WwTW 14\% } \\
\text { Non-WwTW 5\% }\end{array}$ & $\begin{array}{l}\text { APR: } \\
\text { WwTW 21\% } \\
\text { Non-WwTW 5\% }\end{array}$ & $\begin{array}{l}\text { See below for } \\
\text { definition of } \\
\text { bespoke scenario } \\
\text { Estimated } \\
\text { uncertainty range } \\
\text { in brackets }\end{array}$ \\
\hline TBT & $12 \pm 7$ & $6 \pm 3$ & $10 \pm 5$ & $6 \pm 3$ & $5 \pm 3$ & $6(5-11)$ \\
\hline Methyl-Mercury & $47 \pm 8$ & $9 \pm 1$ & $17 \pm 3$ & $13 \pm 2$ & $12 \pm 2$ & $16(13-18)$ \\
\hline HBCDD & Complies & Complies & Complies & Complies & Complies & Complies \\
\hline Cypermethrin & 0 to 3 & 0 to 2 & 0 to 2 & 0 to 1 & 0 & Complies (0-5) \\
\hline PFOS & $4 \pm 11$ & $3 \pm 3$ & $3 \pm 5$ & $2 \pm 4$ & $2 \pm 4$ & $5(0-7)$ \\
\hline PFOA & Complies & Complies & Complies & Complies & Complies & Complies \\
\hline Benzo(a)pyrene & $1110 \pm 61$ & $45 \pm 3$ & $88 \pm 5$ & $84 \pm 5$ & $84 \pm 5$ & $96(90-100)$ \\
\hline Fluoranthene & $144 \pm 52$ & $9 \pm 3$ & $18 \pm 6$ & $16 \pm 6$ & $16 \pm 6$ & $19(12-26)$ \\
\hline DEHP & $45 \pm 5$ & $15 \pm 1$ & $25 \pm 3$ & $18 \pm 2$ & $16 \pm 2$ & $22(18-24)$ \\
\hline BDE47 & $86 \pm 3$ & $42 \pm 2$ & $67 \pm 2$ & $43 \pm 1$ & $38 \pm 1$ & $68(64-70)$ \\
\hline
\end{tabular}

Notes

- APR is annual percentage reduction - the percentage reduction in inputs to the environment achieved in

Illustrations of the rates of change of environmental concentrations shown in Figures 3 and 4 are for APR reductions of $10 \%$ in both types of inputs (scenario 2). The purpose of these figures is to provide a visualisation of the different cases. The decay curves displayed in these figures are for chemicals for which reliable sediment and biota EQS are available. There is a bias towards biota standards owing to them being considered the sensitive environmental receptors, often associated with the risk of secondary poisoning on higher organisms, including humans. Plots for the other substances are provided in ESI Figures S1 and S2. 

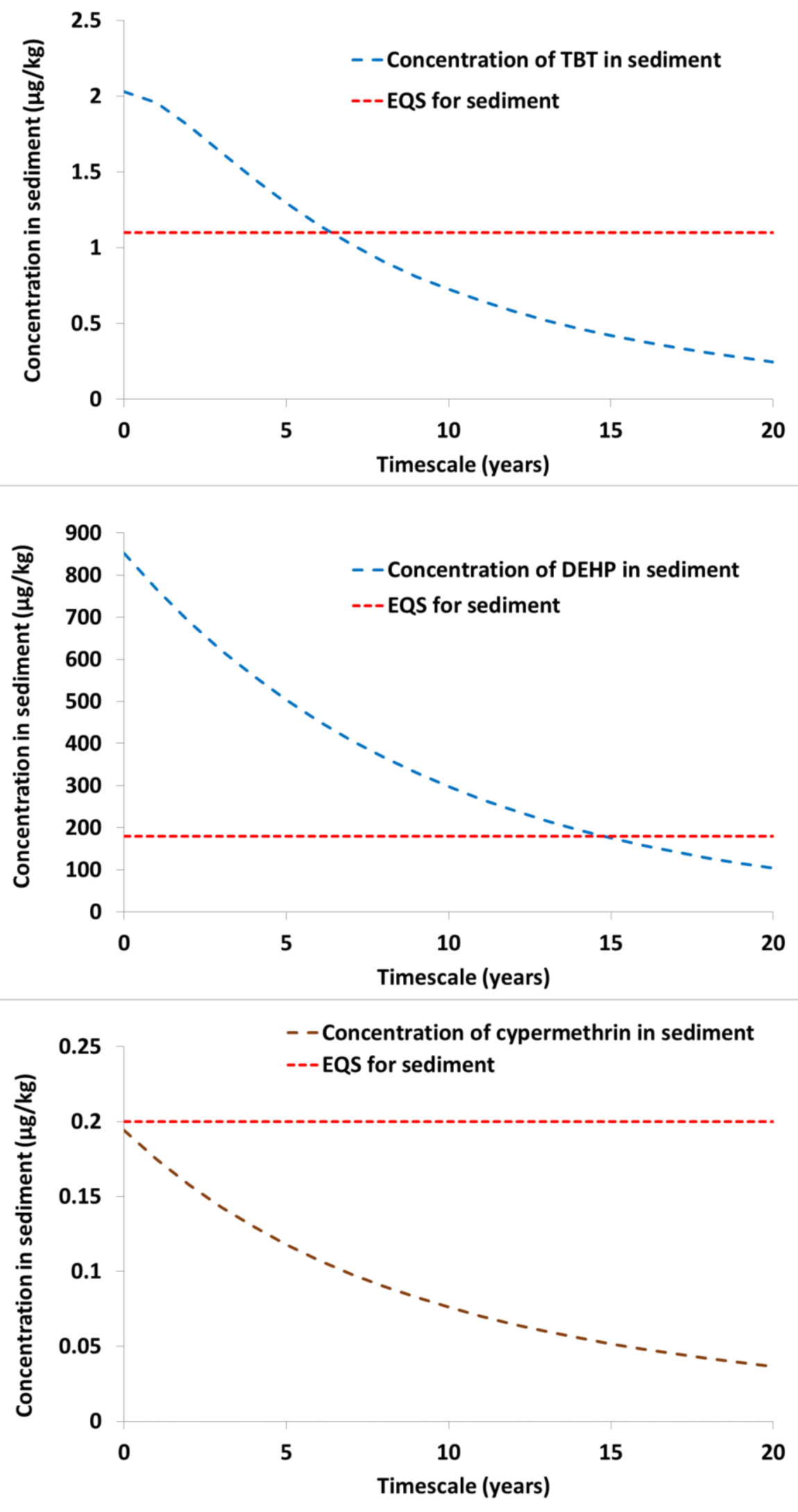

Figure 3 Illustrations of decline in sediment contaminant concentrations for APR reductions of $10 \%$ in both types of inputs (scenario 2 ) 

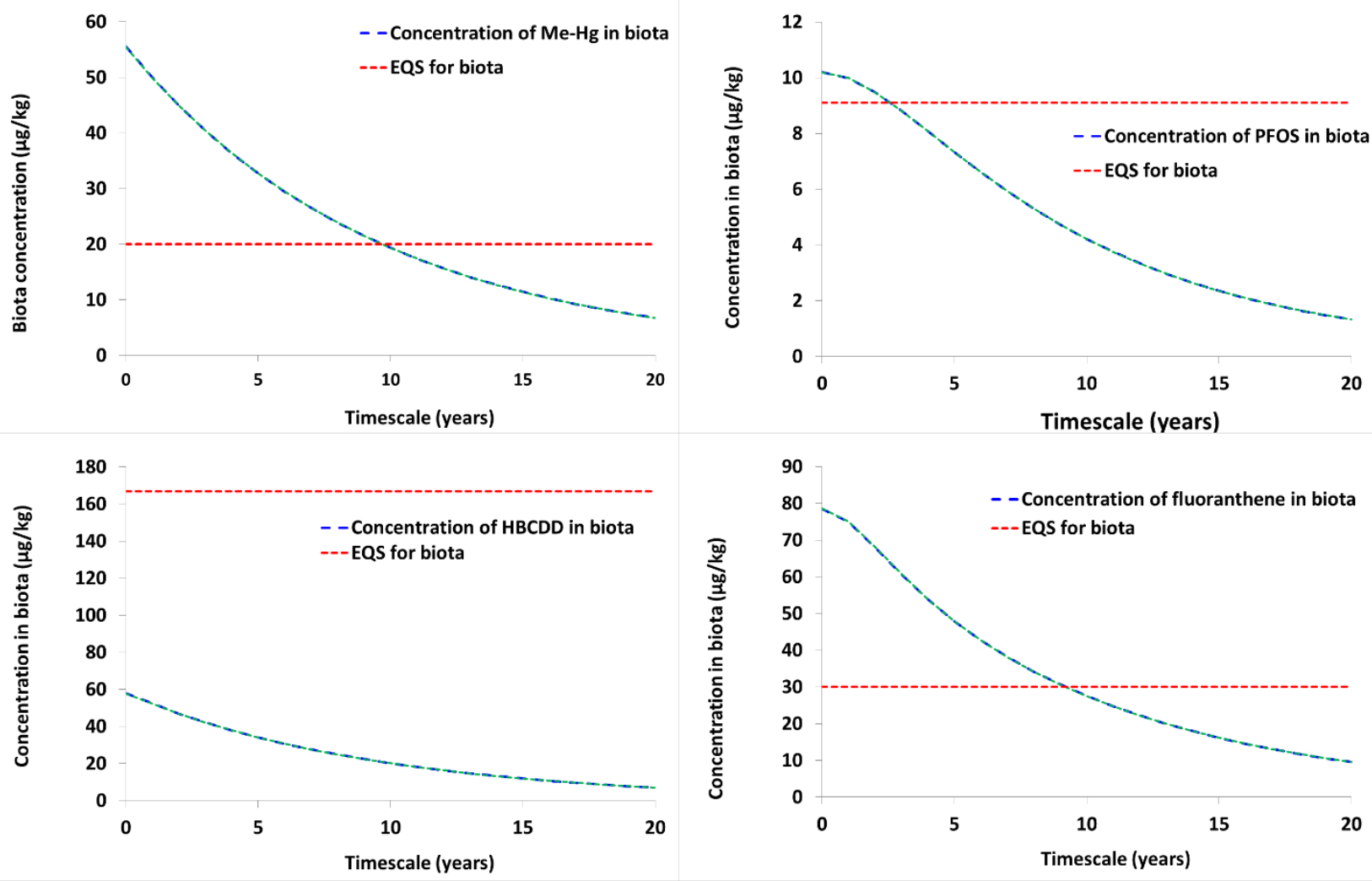

Figure 4 Illustrations of decline in biota contaminant concentrations for APR reductions of $10 \%$ in both types of inputs (scenario 2 ) 
540 Reported estimations of trends in POP concentrations in water/sediment/biota are, as noted 541 above, often based on site specific case studies for individual contaminants. These studies 542 frequently result in markedly different estimates in trends. This, in turn, makes it difficult to 543 compare between studies and with the generic approach derived here. However, at least for 544 the wastewater inputs to the aquatic environment, data required for such a comparison are 545 now available from the extensive, multi-determinand survey of wastewater treatment works' 546 quality provided by the UKWIR Chemicals Investigation Programme (CIP) ${ }^{(42)}$. This would 547 provide a baseline for a modelling approach that took input data and projected its likely effect 548 on biota concentrations and the extent to which regulatory compliance might be achieved in 549 the future.

550 The UKWIR CIP is a monitoring programme provided data between 2013, 2016, 2017, 2018 551 and 2019(42). Effluent quality data were obtained for more than 700 sites and provided the opportunity to estimate a monitoring-based value for an annualised percentage rate of change of POP levels in effluent. Table 3 summarises the rates of changes (as annualise percentage rate (APR)) observed for the substances of interest with additional date provide for benzo(a)pyrene and fluoranthene as examples of contaminants that would not have changed in concentration because unlike the other substances they had not been subjected to control measures in the period concerned.

The table shows that, given the observed variability of measurements, an APR over six years as large as approximately $5 \%$ would be likely to have been detected as statistically significant.

Table 3. Measured variability of concentrations over a six year period (2013-2019)

\begin{tabular}{|l|c|c|c|}
\hline Substance & $\begin{array}{l}\text { Annualised \% rate } \\
\text { of change }\end{array}$ & P value for trend & $\begin{array}{l}\text { Stat sig? } \\
\mathbf{p = 0 . 0 5}\end{array}$ \\
\hline Triclosan & -18 & 0.0005 & sig \\
\hline DEHP & -7 & 0.02 & sig \\
\hline TBT & -17 & 0.002 & sig \\
\hline BDE47 & -15 & 0.0005 & sig \\
\hline Benzo(a)pyrene & -4 & 0.26 & ns \\
\hline Fluoranthene & 2.4 & 0.3 & ns \\
\hline
\end{tabular}


Figures for the fluorocarbons, cypermethrin and HCBDD are not shown because monitoring data were not obtained in the earliest year of the programme, resulting in the assessment period being too short for meaningful analysis.

These results indicate that the scenarios for which the decay tool was tested are not unrealistic in relation to the magnitudes of environmental change that might be achieved by current control measures. This prompts the conclusion that, provided these APR values can be sustained over the next five to ten years, current measures will indeed succeed in effluent concentration at the great majority of WwTW sites that are below the regulated values. Clearly, this will need to be confirmed by monitoring, although other European countries have also reported declining concentrations of PFOS over the past decade, although the picture is never completely clear as in heavily urbanised or industrialised areas trends may be masked by legacy pollution(54).

This tool represents a plug flow environment with finite spatial (downstream) extent, with dynamic accumulation or loss occurring in the sediment due to wastewater (and other) loadings, equilibrium biosorption to sediments, and first-order decay. Similar to previous models(17-19) the formulation allows for a simple exponential approach to a new "steady state", as the loading input is modified. Although the Mackay models include more environmental compartments (typically water, air, soil, sediments, and biota), they also require some form of adaptation to represent the 1-D fate and transport of a river because the media compartments are based on the premise of a continuous stirred tank reactor (CSTD). The CSTD approach have been applied to the environmental fate in terms of spatial range and temporal persistence of lindane, hexachlorobenzene, dieldrin and dioxins for example, in compartments such as soil(27).

The development and use of the tool described here takes account of a combination of modelling and monitoring to provide support for current control strategies and for the use of the tool for new substances of interest in the future. This predictive model therefore allows the opportunity to identify the required reduction in any given chemical source (point or diffuse) to meet a required EQS within a given time period. Any potential mitigation measures can then be assessed on a cost-benefit basis to identify the most appropriate solutions. Furthermore, the model will show whether a biota EQS is achievable and the relative importance of diffuse versus point sources. 


\section{Conclusions}

This investigation has examined an approach to comparing the impact of control strategies of different effectiveness for environmental contamination by trace substances.

Comparisons made on the same basis suggest that:

1. Some substances of current interest (HBCDD, cypermethrin, PFOA) appear not to present generic compliance problems - based on current estimates of mean WwTW effluent concentrations.

2. Concentrations of other substances (methyl-mercury, TBT, PFOS) are above the relevant quality criterion, but given a $10 \%$ annual percentage reduction that is evident in current data, these substances might be compliant with regulations in a relatively short time.

3. The remaining substances of those examined (BDEs, benzo(a)pyrene, fluoranthene and DEHP) appear to present more intractable longer-term compliance problems.

\section{Conflicts of interest}

There are no conflicts of interest to declare.

\section{Acknowledgements}

The authors acknowledge the support and advice of the Department of the Environment, Food and Rural Affairs, the Environment Agency and the Permission of UKWIR to use data from the Chemicals Investigation Programme (UKWIR, 2018).

\section{References}

1. R.H. Hall. A new threat to public health: organochlorines and food. 1992, Nutr. Health, 8 (1), 33-43.

2 IMO. International Maritime Organisation. International Convention on the Control of Harmful Anti-fouling Systems on Ships. 2001.

3. Commission, E. Commission Implementing Regulation (EU) 2018/1130 of 13 August 2018 approving cypermethrin as an existing active substance for use in biocidal products of product-type 18 (Text with EEA relevance.), 2018.

4. Commission, E. Commission Regulation (EC) No 1881/2006 of 19 December 2006 setting maximum levels for certain contaminants in foodstuffs (Text with EEA relevance), 2006. 
5. Commission, E. Council Directive 67/548/EEC of 27 June 1967 on the approximation of laws, regulations and administrative provisions relating to the classification, packaging and labelling of dangerous substances, 1967.

6. Commission, E. Council Directive 91/271/EEC of 21 May 1991 concerning urban waste-water treatment, 1991.

7. Commission, E. Directive 2000/60/EC of the European Parliament and of the Council of 23 October 2000 establishing a framework for Community action in the field of water policy, 2000.

8. Commission, E. Commission Regulation (EU) No 757/2010 of 24 August 2010 amending Regulation (EC) No 850/2004 of the European Parliament and of the Council on persistent organic pollutants as regards Annexes I and III Text with EEA relevance, 2010.

9. Commission, E. Commission Regulation (EU) 2016/293 of 1 March 2016 amending Regulation (EC) No 850/2004 of the European Parliament and of the Council on persistent organic pollutants as regards Annex I (Text with EEA relevance), 2013.

10. Commission, E. Commission Regulation (EU) 2017/1000 of 13 June 2017 amending Annex XVII to Regulation (EC) No 1907/2006 of the European Parliament and of the Council concerning the Registration, Evaluation, Authorisation and Restriction of Chemicals (REACH) as regards perfluorooctanoic acid (PFOA), its salts and PFOArelated substances, 2017.

11. ECHA Data on manufacture, import, export, uses and releases of hbcdd as well as information on potential alternatives to its use, 2009.

12. ECHA Annex XV restriction report proposal for a restriction substance name:

Perfluorooctanoic acid (PFOA), PFOA salts and PFOA-related substances, 2014.

13. S. Comber, R. Smith, P. Daldorph, M. Gardner, C. Constantino \& B. Ellor. Development of a Chemical Source Apportionment Decision Support Framework for Catchment Management. Environ. Sci \& Technol. 2013, 47 (17), pp. 9824-9832.

14. Gardner, M., Jones, V., Comber, S., Scrimshaw, M. D., Coello-Garcia, T., Cartmell, E., Lester, J., B. Ellor. Performance of UK wastewater treatment works with respect to trace contaminants. Sci. of the Tot Environ. 2013, 456 pp. 359-369.

15. M. Gardner, S. Comber, M. Scrimshaw, E. Cartmell, J. Lester, B. Ellor. The significance of hazardous chemicals in wastewater treatment works effluents. Sci. of the Tot Environ. 2012, 437, 363-372.

16. S Comber, M. Gardner, P. Sorme, D. Leverett, B. Ellor. Active pharmaceutical ingredients entering the aquatic environment from wastewater treatment works: A cause for concern?. Sci. of the Tot Environ. 2018, 613, 538-547.

17. D. Mackay. Finding fugacity feasible. Environ Sci Technol. 1979, 13(10):1218-1223.

18. D. Mackay, S. Paterson. Evaluating the multimedia fate of organic chemicals: a level III fugacity model. Environ. Sci. \& Technol. 1991, 25 (3): 427-436.

19. F. Wania, D. Mackay. The evolution of mass balance models of persistent organic pollutant fate in the environment. Environ. Poll., 1999, 100, 223-240.

20. D. MacKay, E. Webster, I. Cousins, K. Forster, T. Gouin. An intrroduction to multimedia models (CEMC Report No. 200102). Canadian Moelling Centre, Peterborough, Canada. 2001.

21. S.D. Choi, F. Wania. On the reversibility of environmental contamination with persistent organic pollutants. Environ. Sci. Technol. 2011, 45, 20, 8834-8841. 
22. T. Gouin, F. Wania. Time trends of arctic contamination in relation to emission history and chemical persistence and partitioning properties. Environ. Sci. Technol. 2007, 41, 17, 5986-5992.

23. L. Li, F. Wania. Occurrence of single- and double-peaked emission profiles of synthetic chemicals. Environ. Sci. Technol. 2018, 52, 8, 4684-4693.

24. C.E. Cowan-Ellsberry, M.S. McLachlan, J.A. Arnot, M. MacLeod, T.E. McKone, F. Wania. Modeling Exposure to Persistent Chemicals in Hazard and Risk Assessment. Int. Environ. Assess. And Man. 2009, 5 (4), 662-679.

25. M. Scheringer. Persistence and spatial range as endpoints of an exposure-based assessment of organic chemicals. Environ. Sci \& Technol. 1996, 30(5), pp.1652-1659.

26. D.H. Bennett, T.E. McKone, M. Matthies, W.E. Kastenberg. General formulation of characteristic travel distance for semivolatile organic chemicals in a multimedia environment. Environ. Sci. Technol.,1998, 32(24), 4023-4030.

27. D.H. Bennett, W.E. Kastenberg, T.E. McKone. General formulation of characteristic time for persistent chemicals in a multimedia environment. Environ. Sci. Technol., 1999, 33(3), 503-509.

28. D.H. Bennett, T.E. McKone, W. Kastenberg. Characteristic time, characteristic travel distance, and population based potential dose in a multimedia environment: a case study. LBNL Report-45815, Environmental Energy Technology Division, 2000.

29. M. MacLeod, A.J. Fraser, D. Mackay. Evaluating and expressing the propagation of uncertainty in chemical fate and bioaccumulation models. Environ. Toxicol. \& Chem.: An Int. Journal, 2002, 21(4), 700-709.

30. J. Klasmeier, M. Matthies, M. Macleod, K. Fenner, M. Scheringer, M.Stroebe, A.C. Gall, T. Mckone, D.De Meent, F. Wania. Application of multimedia models for screening assessment of long-range transport potential and overall persistence. Environ. Sci. Technol. 2006, 40, 1, 53-60.

31. M. Tao, A.A. Keller. ChemFate: A fate and transport modeling framework for evaluating radically different chemicals under comparable conditions. Chemosphere, 2020, 255, 126897.

32. L. Ceccaroni, U. Cortes, M. Sanchez-Marre. OntoWEDSS: augmenting environmental decision-support systems with ontologies. Environ. Modelling \& Software, 2004, 19 (9), pp. 785-797.

33. K.W. Chau. An ontology-based knowledge management system for flow and water quality modeling. Adv. in Engineering Software, 2007, 38 (3), pp. 172-181.

34. Z. Xiaomin, Y. Jianjun, H. Xiaoci, C. Shaoli. An Ontology-based Knowledge Modelling Approach for River Water Quality Monitoring and Assessment. Procedia Comp. Sci., 2016, 96, 335-344.

35. X.P. Wen, X.F. Yang. Monitoring water quality using remote sensing data mining. In: Funatsu, Kimito (Ed.), Chapter in Book: Knowledge Applications in Data Mining. 2011, InTech ISBN: 978-953-307-154-1.

36. K. Kolli K., R. Seshadri. Ground Water Quality Assessment using Data Mining Techniques. Int. J. Comp. Appl. 2013, 76 (15), 39-45.

37. M. Cossentino, F. Raimondi, M.C. Vitale. Bayesian models of the PM10 atmospheric urban pollution, in Latini, G. and Brebbia, C.A. (eds.) Air Pollution Ix. Southampton: Wit Press, 2001, pp. 143-152.

38. C. Tang, Y. Yi, Z.F. Yang, J. Sun. Risk analysis of emergent water pollution accidents based on a Bayesian Network. J. of Environ. Man., 2016, 165, 199-205. 
39. M.A. Oprea. A knowledge modelling framework for intelligent environmental decision support systems and its application to some environmental problems. Environ. Model. \& Software, 2018, 110, 72-94.

40. P. Whitehead, L. Jin, J. Crossman, S. Comber, P. Johnes, P. Daldorph, N. Flynn, A.L. Collins, D. Butterfield, R. Mistry, R. Bardon, L. Pope, R. Willows. Distributed and dynamic modelling of hydrology, phosphorus and ecology in the Hampshire Avon and Blashford Lakes: evaluating alternative strategies to meet WFD standards. Sci Tot. Environ, 2014, 481, 157-166.

41. F. Rigét, A. Bignert, B. Braune, J. Stow, S. Wilson. Temporal trends of legacy POPs in Arctic biota, an update. Sci. of the Tot. Environ., 2010, 408 (15), 2874-2884.

42. UKWIR. UK Water Industry Research. The Chemical Investigations Programme Phase 2, 2015-2020 - Initial Findings, 2018, Volumes 1-4, ISBN 184057851 3. 2018.

43. S. Replinger, S. Katka, J. Toll, B. Church, L. Saban. Recommendations for the derivation and use of biota-sediment bioaccumulation models for carcinogenic polycyclic aromatic hydrocarbons. Int. Environ. Assess. And Man., 2017, 13 (6), 10601071.

44. G. Einsele. Sedimentary basins: Evolution, facies, and sediment budget. 2000, ISBN 3-540-66193-x, Springer-Verlag.

45. M. Bozym, G. Siemiatlowki. Characterization of composted sewage sludge during the maturation process: a pilot scale study. Environ. Sci. and Poll. Res., 2018, 25, 3433234342.

46. S.L. Simpson, G.B. Batley, A.A. Chariton. Revision of the ANZECC/ARMCANZ Sediment Quality Guidelines. CSIRO Land and Water Science Report 08/07. CSIRO Land and Water. CSIRO Land and Water Science Report, 2013, Water for a Healthy Country Flagship Report series ISSN: $1835-095 \mathrm{X}$ - corrected to $20 \%$ organic carbon.

47. M. Crane, I. Johnson, N. Sorokin C. Atkinson C., S.J. Hope. Proposed EQS for Water Framework Directive Annex VIII substances: cypermethrin Science Report: SC040038/SR7 SNIFFER Report: WFD52(vii) 2007, ISBN: 978-1-84432-657-0

48. K. Kumar, G. Sundarmoorthy P.K. Ravichandran G.K. Girijan, S. Sampath, B.R. Ramaswamy. Phthalate esters in water and sediments of the Kaveri River, India: environmental levels and ecotoxicological evaluations. Environ. Geochem. and Health, 2014, 37(1), 83-96.

49. G. Manache, C.S. Melching. Identification of reliable regression-and correlation-based sensitivity measures for importance ranking of water-quality model parameters. Environ. Model. \& Software, 2008, 23(5), 549-562.

50. Q. Lu, M.D. Jurgens, A.C. Johnson, C. Graf, A. Sweetman, J. Crosse, P. Whitehead. Persistent Organic Pollutants in sediment and fish in the River Thames Catchment (UK). 2017, Sci Total Environ, 576, 78-84.

51. J. Kim, D. Mackay, D.E. Powell. Roles of steady-state and dynamic models for regulation of hydrophobic chemicals in aquatic systems: A case study of decamethylcyclopentasiloxane (D5) and PCB-180 in three diverse ecosystems. Chemosphere, 2017, 175, 253-268.

52. M Honti, K. Fenner. Deriving Persistence Indicators from Regulatory Water-Sediment Studies - Opportunities and Limitations in OECD 308 Data. 2015, Environ. Sci \& Technol. 49 (10), 5879-5886.

53. A. Radomyski, E. Giubilato, P. Ciffroy, A. Critto, C. Brochot, A. Marcomini. Modelling ecological and human exposure to POPs in Venice lagoon - Part II: Quantitative 
uncertainty and sensitivity analysis in coupled exposure models. Sci. Total. Environ., 2016, 569-570, 1635-1649.

54. A. Fliedner, N. Lohmann, H. Rüdel, D. Teubner, J. Wellmitz, J. Koschorreck. Current levels and trends of selected EU Water Framework Directive priority substances in freshwater fish from the German environmental specimen bank. 2016, Environ. Poll. $216,866-876$. 